Pagdanhay at pagtunghay ng mga naratibong danas dulot ng COVID-19 sa Lipunang Pilipino: Ang bagong kahimtang

Lagunsad, Rusell Irene L. $\<$

Notre Dame of Greater Manila, Philippines (lagunsadrusellirene@gmail.com)

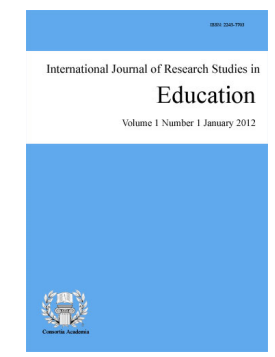

ISSN: $2243-7703$ Online ISSN: 2243-7711

OPEN ACCESS

\title{
Abstract
}

Dulot ng nangyaring pandemiko na nangyari sa buong mundo, ang lipunang Pilipino ay nagkaroon ng malaking pagbabago. Naging kumplikado ang estado ng buhay ng maraming Pilipino. Ito na ngayon ang tinatawag ng marami na "bagong normal" o "bagong kahimtang" sa wikang Hiligaynon. Layon ng pananaliksik na mula sa mga ibinahaging iba't ibang kuwento ng karanasan ng mga kinapanayam ay makabuo ng danhay ng mga naratibo hinggil sa naging dulot ng pandemiko sa tao at bansa. Mula roon ay sinipat ang mga kalagayang ito, sinuri at dinalumat ng mananaliksik ang mga biglaang pagbabagong dinanas ng lipunan tungo sa transisyong dihital. Inilapat ang Sikolohiyang Pilipino ni Virgilio Enriquez sa pagbuo ng papel. Ito ang sikolohiyang bunga ng karanasan, kaisipan at oryentasyong Pilipino. Ito ang mga metodo na ginamit para sa pagtatarok ng diwa ng mga kalahok. Lumitaw na sa bagong kahimtang ng lipunan, napakalaking gampanin ng internet world sa pamumuhay ng mga Pilipino. Sa panahong lahat ay nasa bahay na lamang, halos lahat ay nakatutok sa kanilang mga social media accounts upang pagkunan ng napapanahong impormasyon. Ang magastos at masakripisyong paraan ng pag-ani ng sertipiko ng mga guro para sa kanilang promotional rankings at self- development ay naging libre nalang. Sa isang iglap ay biglang nag-iba ang meeting rooms para sa mga pagpupulong hindi na isang silid, hindi na rin function hall para sa mga seminars o silid-aralan para sa pagtuturo at hindi lamang distansiya ng tao sa tao ang naganap, kundi maging ang distansya ng tao sa kaniyang pangangailangan upang mabuhay.

Keywords: Lipunang Pilipino; bagong kahimtang; manggagawang Pilipino; danas; panayam; social media 


\section{Pagdanhay at pagtunghay ng mga naratibong danas dulot ng COVID-19 sa Lipunang Pilipino: Ang bagong kahimtang}

\section{Panimula}

Marso 16, 2020 ang gobyerno ng Pilipinas ay nagdesisyon na sasailalim ang buong Metro Manila sa Enhanced Community Quarantine (ECQ) bilang aksyon ng pamahalaan sa mabagsik na Coronavirus Disease 2019 (COVID-19) na nagsimulang kumalat sa Wuhan, Hubei Province of China noong Disyembre 2019 ayon sa timeline na naitala ng World Health Organization (2020), at ngayon ay patuloy na inaatake ang buong mundo. Magtatapos sana ang ECQ sa Metro Manila sa ika-12 ng Abril ngunit dahil sa rekomendasyon ng Inter-Agency Task force on Emerging Infectious Disease (IATF-EID) ito'y mas pinatagal pa hanggang ika-30 ng Abril dahil sa patuloy na paglobo ng bilang ng mga positibo sa virus at sa bilang ng mga namamatay. Maging ang mga probinsiya na nagkaroon ng positibong kaso ng COVID-19 ay sumailalim na rin sa ECQ.

Sa ilalim ng ECQ, ibinaba ng pamahalaan sa lahat ng Local Government Unit (LGU) ang mahigpit na pagpapasunod sa mga panuntunan na dapat sundin habang naka-ECQ tulad ng pagbabawal na lumabas ng bahay, maliban na lamang kung kailangang mamalengke, pumunta sa groseri o bumili ng gamot basta may quarantine pass at may suot na facemask at ito ay may susunding oras alinsunod sa ibinaba ng LGU at dapat ay may isang metrong layo bawat isa. Hindi maari ang pag-eehersisyo sa labas ng bahay, ipinagbabawal din ang mga pagtitipon, walang pampublikong sasakyan ang maaaring bumiyahe gayundin ang mga domestic flights at limitado lamang ang mga international flights. Ipinatupad ang curfew hours mula 5:00 n.u- 8:00 n.g kinabukasan at ang may liquor ban. Walang klase sa mga paaralan kaya't naudlot ang semestre at kaniya- kaniyang paraan ang mga unibersidad at paaralan upang mag-isip ng alternatibong solusyon kung paano bibigyang marka ang mga estudyante dahil kailangan na nilang tapusin ang taong panuruan. Gayundin din ang mga pasok sa pabrika't opisina ay kanselado na at kung maaaring work from home muna ngunit ang tinatawag na mga frontliners ay patuloy na papasok upang magbigay serbisyo sa taong-bayan tulad ng mga doktor, nurse, delivery man, kolektor ng basura, magsasaka, tanod, pulis, sundalo, volunteers, cashier sa mga grocery store, pharmacist at iba pa (ABS-CBN, 2020).

Noong Mayo 1, mas napahaba pa ito hanggang Mayo 15 ngunit sa mga piling lugar na lamang na maikokonsidera na high-risk areas samantalang ang mga low at moderate-risk areas ay sasailalim naman sa General Community Quarantine o Less Strict Quarantine (GCQ) at nang sumapit ang Mayo 12 inanunsyo ni Presidential Spokesperson Harry Roque sa televised press briefing na ang Metro Manila, Laguna at Cebu City ay mapupunta naman ngayon sa Modified ECQ mula Mayo 16 hanggang 31 dahil ito ang mga lugar na nasa kategoryang high-risk places (Esguerra, 2020). Inanunsyo naman noong Mayo 30 na ang Metro Manila, kasama ang iba pang lugar ay sasailalim na sa GCQ.

\section{Metodo ng pananaliksik}

Ang pamagat ng papel na ito ay "Pagdanhay at Pagtunghay ng mga Naratibong Danas Dulot ng COVID-19 sa Lipunang Pilipino: Ang Bagong Kahimtang”. Nabanggit ang mga hindi pamilyar na salita sa wikang Filipino tulad ng "pagdanhay" na ayon sa Diksyonaryo.Ph (n.d.) mula sa salitang-ugat nito na "danhay" na kasingkahulugan ng "banghay" at kahulugan na "pangkalahatang takbo ng isang salaysay" at "pagtunghay" na ang ibig sabihin ay "pagsipat o pagtingin nang mabuti”. Mula sa mga ibinahaging iba't ibang kuwento ng karanasan ng mga kinapanayan, nakabuo ng danhay ng mga naratibo hinggil sa naging dulot ng pandemiko sa tao at bansa. Mula roon ay sinipat ang mga kalagayang ito, sinuri at dinalumat ng mananaliksik ang mga biglaang pagbabagong dinanas ng lipunan tungo sa transisyong dihital, pagtatagpo ng tradisyon at teknolohiya at ang mas lalong naging abang kalagayan ng mga simpleng Pilipino. Ang salitang "bagong kahimtang" naman na ayon kay Villan (2020a) sa kaniyang Facebook post, na mula sa salitang Hiligaynon ang "kahimtang”, na ang 
ibig sabihin ay "kalagayan, ayos o kahingian". Mas may lapit sa ating pagka-Pilipino sa halip na tawagin nating "new normal" o "bagong normal".

Ito ay isang naratibong pananaliksik na naglalayong kolektahin at isalaysay ang iba't ibang danas ng mga partikular na tao bunga ng biglaang pagbabago ng lipunan dulot ng isang kaganapan kaya tatalakayin ang mahalagang tampok na ito nagdulot ng malaking epekto sa kanilang buhay. Inilapat ang Sikolohiyang Pilipino ni Virgilio Enriquez sa pagbuo ng papel na ito. Ito ang sikolohiyang bunga ng karanasan, kaisipan at oryentasyong Pilipino. Ang Sikolohiya sa Pilipinas ay bunga ng pagkakasunud-sunod ng mga pangyayaring may kinalaman sa sikolohiya sa ating bayan (Enriquez, 2015). Ito ang mga metodo na ginamit para sa pagtatarok ng diwa ng mga kalahok. Subok na ang mga pamamaraan na ito na lumikom ng mga impormasyon sa kulturang Pilipino at angkop sa pag-uugali at pang-araw-araw na pamumuhay ng mga Pilipino.

Mula sa "pagmamasid" sa paligid, sa paglabas- labas ng mananaliksik ay nakalipon ng mga ideya na maaaring mailagay sa papel na ito at mga pagbibigay-puna sa mga namasdan, nasaksihan nabasa at napanood. "Pagtatanong-tanong" naman sa mga nakapanayam gamit ang teknolohiya (messenger video call) dahil nga mahigpit ang batas tungkol sa paglalabas- labas noon, ito ang pinakamadaling paraan upang makakonekta sa mga taong maaaring makadagdag ng datos sa papel na ito at upang maabot rin natin ang maaaring kapanayamin na nagtatrabaho sa ibang bansa para sa balanseng pagtingin sa kalagayan ng mga Pilipino hindi lamang sa Pilipinas ngayong may pandemiko. Ang "pakikiramdam" ay kasama rin dahil tinatantiya ng mananaliksik kung maaari na bang makapagsagawa ng panayam sa mga napiling kalahok lalo na't ang iba ay apektado ang kalusugan ng kanilang pag-iisip bunga ng mga negatibong kaganapan ngayon sa mundo at ang "pagdalaw-dalaw", may dalawang beses na nagbalik-balik ang mananaliksik sa bahay ng isang respondente upang una ay makipagpalagayang-loob muna, mangumusta dahil halos dalawang buwan din na hindi nakapagkita o nakapag-usap. Nakahihiya din naman na basta na lamang pupunta at magsasagawa ng panayam at nakipag-ayos pa ng iskedyul kung kailan sila maaaring makausap uli patungkol naman sa isinasagawang papel ng mananaliksik. Sinigurado naman na ang pisikal na distansiya na isang metro ay isinagawa at madali lang ang akses sa lugar dahil hindi naman ito kalayuan sa tirahan ng mananaliksik, lalakarin lamang.

Ang uri ng panayam na lumitaw ay "unstructured”. May gabay ngunit mas kumbersasyonal dahil malaya ang daloy ng pakikipagtalasan sa pagitan ng tagapanayam at kakapanayamin na tila nakikipagkwuwentuhan lamang nang sa gayon hindi maging mabigat at pormal ang dating sa kanila. Ang batayan naman sa informants o research partner ay "individual" dahil paisa-isa lamang ang pagharap ng mananaliksik sa bawat respondente ayon sa mga oras na ibinigay nila at ang uri ng tanong ay ibinatay sa kanilang "behavior, opinions/values at feelings" (Tan, 2020). Ang mga naratibong ibinahagi na umugat sa mga personal na danas ng mga kalahok ang bubuo at magpapatibay sa nilalaman ng papel na ito. Ang mga dagdag na datos naman na makapagpapatotoo sa mga salaysayin ay kinuha sa mga artikulo, balita at mga websites online dahil hindi pa maaaring lumabas noon upang makapunta sa mga silid-aklatan.

\section{Resulta at pagtalakay}

\subsection{Online balita sa kalagayan ng mga manggagawang Pilipino sa panahon ng pandemya: Mga puna at opinyon}

Sa usapin ng pagkalap ng mga balita, malinaw na sa kasalukuyan ay mas nakaabang ang tao sa social media dahil sa mas mabilis ang pagpo-post dito at malawak ang akses dahil maging ang kaganapan sa ibang mga bansa ay naibabalita na hindi sinasakop ng mga balita sa telebisyon. Mula sa iba't ibang mga websites ay madali itong naili-link sa Facebook. Nais magbigay ng mananaliksik ng ilang puna o opinyon sa mga artikulo o balitang nabasa sa social media na umagaw ng atensyon sa mga tao. Una na diyan ang balita noong Mayo 11 mula sa Philippine Star. Mayroong mga construction workers na hindi nakauwi sa kani-kanilang mga probinsiya dahil inabutan na nang implementasyon ng ECQ at hindi na rin sumusweldo dahil sila ay "no work, no pay basis". 
Lagunsad, R. I. L.

Sila ay makikita na nanlilimos na lamang sa mga motorista at mga dumaraang pribadong sasakyan sa kahabaan ng Macapagal Boulevard sa Pasay City.

Marami sa mga nagtatrabaho sa NCR ay mula sa mga kalapit lalawigan, tulad ng Cavite, Bulacan, Laguna, Pampanga at iba pa dahil sa hindi pantay na pagbibigay ng minimum wage sa mga manggagawa. Binanggit ito ni San Juan (2020) sa webinar na kanilang isinagawa sa Tanggol Wika na marami na ang kumukwestyon sa sistemang ito sapagkat ang mga gastusin at bilihan sa probinsiya at Metro Manila ay magkatulad na rin. Bunga nito mayroong mga mambabatas sa kongreso na nagnanais na magkaroon ng isang pambansang minimum wage sa lahat ng panig ng Pilipinas nang sa gayon lahat ng manggagawa ay magtamasa ng istandard na lebel ng pamumuhay.

Ikalawa, ang ulat ni Hazel (2020) sa Pinas Balita noong Mayo 19 tungkol sa tindero ng isda. Kinilala siya bilang si Joseph "Mang Dodong" Jimeda. Isa si Mang Dodong sa napakaraming violators sa gitna ng umiiral na enhanced community quarantine. Ang 58-anyos na fish vendor ay nakatira sa Brgy. 31, Caloocan City at upang matustusan ang kanyang pamilya, nagpunta ito sa Navotas Fish Port upang mamili ng mga ititindang isda. Dala niya ay quarantine pass na sumasakop lamang sa Caloocan. Siya'y inaresto ng mga awtoridad at 12 araw na ipinamalagi muna sa Navotas Sports Complex. Hindi ito nalaman ng kaniyang mga kapamilya sapagkat wala naman siyang cellphone. Pinagpiyansa ang kaniyang pamilya ng halagang P3, 500 upang makauwi siya. Pumukaw ng atensyon sa mga netizens ang naturang balitang ito. Marami ang nahabag at kumikiling sa matanda sapagkat ang hangad lamang naman niya ay may maiuwing maipangkakain sa pamilya. Naungkat tuloy ang mga kaliwa't kanang pagbibigay pabor sa mga pulitiko o nakatataas na lumabag din sa batas ukol sa ECQ. Ang pobreng matanda ay hindi binigyan ng konsiderasyon samantalang ang masasabi nating "may kaya" sa lipunan na nakapaglibot pa sa ospital, opisyales na nakapagdaos pa ng piging ay napalampas at pinairal lang daw ang "compassion".

Ikatlo, ang balita mula sa website ng Balitambayan noong Hunyo 2, dahil binuksan na ang NCR sa General Community Quarantine, maaari nang makapasok sa trabaho ang mga manggagawang Pilipino ngunit limitado ang transportasyon sa Metro Manila. Napakaraming tao na matiyagang naghintay ng masasakyan sa ilalim ng mainit na panahon sa unang araw ng general community quarantine sa Metro Manila. Sa unang araw pa lamang ng GCQ ay samutsaring hirap na ang dinaranas ng mga manggagawang Pilipino na walang ibang nais kundi ang makapagtrabaho lamang upang may maipantustos sa araw-araw nilang gastusin. Sa loob ng dalawang buwan ay labis na ang pagtitiis at pagtitipid ang kanilang ginawa upang maisalba lamang ang bawat araw na may pangamba at takot bunga ng pandemya ngunit sa araw na pinakahihintay upang sana ay kumita muli, nakalulungkot na walang kongkretong plano para sa pampublikong transportasyon na katuwang na noon pa man ng mga Pilipino upang makapaghanapbuhay.

Ayon sa ulat na inilabas ng CNN Philippines (2020), nasa 2,073,362 manggagawa ang nawalan ng trabaho mula noong Abril 24 dahil sa pandemya. Nasa 1.4 milyon ang pansamantalang isinara ang mga pinapasukan at 600, 000 mga personel ang naiulat na bumaba ang sweldo dahil limitado na lamang ang araw ng pasok, rotasyon sa trabaho, forced leave at telecommuting. Sa datos ng IBON (2020), ang dapat daw na family living wage sa NCR upang makapamuhay nang maayos-ayos ay nasa P31, 089 kada buwan na wala pa sa kalahati ng tunay na sinasahod ng mga manggagawa sa minimum wage kada buwan, na sobrang layo naman sa pangarap na buhay ng mga Pilipino na dapat ay kumita ng P120, 000 kada buwan batay sa datos na ibinigay ng NEDA sa Ambisyon Natin 2040. Napakataliwas ng mga datos na ito sa nararanasan ng mga Pilipinong manggagawa. Nakalulungkot na sila ang labis na naaapektuhan sa mga desisyong inilalabas na hindi nakikita ang magiging bunga nito para sa lahat ng uri ng tao sa lipunang kanilang pinamamahalaan.

\subsection{Mga pumatok sa socmed na lalong tinangkilik ng tao}

Batay sa pagbabasa, pag-oobserba, panonood, pagtatanong-tanong ng mananaliksik, ito ang mga lalong sumikat, ginagamit at ginagawa ng tao ngayong pandemiko na unti-unti na ring nagiging natural na bahagi ng

38 Consortia Academia Publishing (A partner of Network of Professional Researchers and Educators) 
bagong buhay ng mga tao.

TikTok Craze - Habang nasa bahay lamang ang milyong mga Pilipinong apektado ng COVID-19, walang pasok sa trabaho o eskwela at tapos nang malinis ang lahat ng sulok ng kanilang bahay ay inaatake na nang sobrang kabagutan, kaya't kung ano-anong maaaaring mapaglibangan ang kanilang ginagawa. Mapabata man o matanda, artista man o avid fan, simpleng mamamayan man o pulitiko ay nahuhumaling sa mga video trends na napapanood sa mga social media accounts. Ito ay isang social network app na produkto ng ByteDance, isang Chinese tech- company na pinatatakbo ng CEO na si Zhang Yiming at kumikita na ang kumpanya ng halos \$75 bilyon. Dinala ito sa international market taong 2017 at unang tinangkilik ng mga bansa sa Asya (Leskin, 2020).

Si G. Jose (panayam sa messenger, Hunyo 3, 2020), nagsimula siyang gumamit ng TikTok noong 2019 at nakapag-upload na nang humigit sa 120 mga videos sa kaniyang account. Nitong pandemya ay mas napadalas ang paggamit niya ng TikTok bunga na rin ng sobrang kabagutan sa bahay. Sa isang araw ay nakagagawa siya ng mga 5-6 videos. Para sa kaniya ang TikTok ay isang instrumento upang maipahayag ang iyong sarili’t paniniwala, maging masaya at makapagpasaya ng iba lalo na ngayon na maraming maaaring maging dahilan ng ating kalungkutan.

Karagdagan pa, nagbigay ng donasyon ang TikTok ng P50 milyon sa Philippine General Hospital Medical Foundation upang maipagpatuloy na malabanan ng bansa ang COVID-19. Inaasahan ng TikTok PH na makatutulong ito nang malaki sa mga frontliners at medical workers na nagsasakripisyo at isinusuong ang kanilang sarili sa laban na ito (Tiangco, 2020). Ang TikTok ay daluyan ng karanasan, ng talento, ng nararamdaman ng tao. Isang pagkukwento at ito ang penomena ng TikTok.

Online selling at delivery services - Habang maraming kumpanya ang naapektuhan sa nangyaring pandemya, mayroong mga negosyo na tila nagkaroon ng dagdag oportunidad at kita ang ganitong kalagayan ng bansa at ilan na rito ay ang mga online seller at delivery services. Ngayon basta may pera ka maaari mong bilhin na lamang online ang mga kailangan mo at hihintayin mo nalang itong maihatid sa iyo ng delivery man o courier. Nakikita ng tao na ang e-commerce ang solusyon sa ganitong sitwasyon ngayon sa usapin ng pagbili ng mga kinakailangan sa tahanan.

Inilahad ni Bb. Rejs (panayam sa messenger, Hunyo 4, 2020) isang online supplier at seller mula pa noong 2015 na mas dumoble ang kita niya ngayong may pandemya. Mula sa P3,000 libong piso kada buwan noon ay naging P6,000 libong piso na ngayon dahil nga nasa bahay lang ang tao at nakababad lang sa Facebook, makikita nila ang mga binebenta online at minsan maeengganyo sila na bumili. Dagdag pa niya, mas dumami pa ang kaniyang reseller ngayon dahil nga marami ang nawalan ng trabaho at naghahanap ng mapagkakakitaan.

Ayon pa sa artikulo ng US Chamber of Commerce (2020), ang delivery services ay isa sa mga negosyong pinakapapatok ngayong may pandemya, dahil ang mga konsyumer ay takot lumabas ng bahay dahil sa pangamba na baka mahawa sila ng sakit at karamihan ay nagtatrabaho na lamang sa bahay, kaya ang nais ng tao ay ihahatid na lamang sa kanila ang kanilang pangangailangan. Instant life! Ganyan na iikot ang buhay ng tao ngayon. Grab, Food Panda at Lalamove ay ilan lamang sa mga delivery services na patuloy na nagbibigay serbisyo sa kasalukuyan at pinipili ng tao upang maipadala o madala ang kanilang mga kailangan.

Instant sertipiko ng mga libreng webinars para sa mga edukador - Ang mga guro sa bansa mapapubliko man o pribado ay kinakailangan na patuloy na palaguin ang kaniyang sarili sa kaniyang espesyalisadong larangan nang sa gayon ay maibigay niya sa kaniyang mga mag-aaral ang lawak ng dunong na inaani niya at nasasaad iyan sa Code of Ethics for Teachers Article 4 Sec.3 (Llego, 2019). Mangyayari ito sa pamamagitan ng kanilang patuloy na pag-aaral sa pagkuha ng masterado at doktoradong digri, pagdalo sa mga seminar, palihan, kumperensiya at iba pa na kailangang gastusan ng malaking halaga at ang kadalasan pa, nagmumula sa mismong bulsa ng mga guro ang pera para sa kanilang professional development.

Nitong nagkaroon ng pandemya, tila hindi na maisasagawa ito kaya lalong nagkaroon ng pag-aalangan, na 
dahil natigil ang pag-eeskwela at paghahanapbuhay ay matitigil na rin ang patuloy na pag-aaral ng mga guro o kung mayroon man ay mas lalong magiging mahal ang bayad ngunit kabaligtaran ang nangyari sapagkat tila naging daan ang pandemya upang mas mabigyan ng oportunidad ang mga edukador na patuloy na umani ng karunungan sa kani-kanilang tahanan nang libre. Umusbong ang kaliwa't kanang mga e-seminars o webinars ng mga organisasyon o publishing house na tatalakay ng mga mahahalagang paksa at napapanahon para sa mga gurong nais magpakadalubhasa, basta mayroon kang malakas na internet connection at smartphone. Makinig at manood ka lamang dahil karamihan ay naka-live stream naman sa Facebook o Youtube, pagkatapos may instant sertipiko ka na. Nasa komportableng ayos ka sa iyong bahay, hindi ka pa napagastos.

Naglitawan pa ngayon ang mga video conferencing app na talaga namang pumatok ngayong may pandemya. Isa sa mga pinakagamitin ngayon sa buong mundo na tila natunugan nila ang mangyayaring ito ay ang Zoom Video Communications. Binanggit ni (Evans, 2020) sa kaniyang artikulo na ayon sa Bernstein Research and Apptopia tumataas ng tatlumpung bahagdan kada taon ang mga nagdo-download ng app na ito at naging top free

app sa Iphones sa United States mula pa noong Marso 18 at umaabot sa 200 milyon na ang gumagamit nito sa buong mundo kada araw magmula noong nagsimula ang pandemya. Nataasan pa nito ang ibang kalaban tulad ng Skype, Microsoft Teams, Google Hangouts at Cisco Webex (Tung, 2020).

Samutsaring danas ng mga Pilipino sa loob at labas ng bansa - Napaunlakan ang mananaliksik na makapanayam ang mga napiling kalahok, maging ang nasa ibang bansa upang maibahagi ang kanilang mga personal na danas sa nangyaring pandemiko mabuti na lamang at may makabagong teknolohiya, na bagaman tila diskonektado man tayo pisikal ay konektado naman tayo birtwal kaya kahit milya-milya ang layo ay magagawa nating makausap at mahingan sila ng kanilang mga eksperyensya para sa kabuuan ng papel na ito.

\section{Binibining Lisa}

Unang kinausap ng mananaliksik ang isang frontliner nurse na nagsisilbi sa isang pribadong ospital sa CAMANAVA. Nagpatago siya sa pangalang Bb. Lisa (panayam sa messenger, Hunyo 5, 2020), isang dialysis nurse at apat na taon na sa serbisyo. Sa buong panahon ng kaniyang pagtatrabaho ito ang pinakamabigat na dagok sa kanilang propesyon. Hindi na siya makauwi sa kaniyang pamilya noon dahil wala nang pampublikong transportasyon mabuti na lamang dahil ang lokal na pamahalaan ay nagbigay ng tulong na libreng akomodasyon, pagkain, kuryente at balikan na hatid-sundo mula sa tinutuluyan hanggang ospital para sa mga frontliners at health workers na malalayo ang tirahan at walang sariling sasakyan. Ibinahagi niya pa na may pasyente silang nagpositibo pala sa COVID-19 at siya ang pinakalaging nag-aasikaso sa pasyente na iyon noon gayundin ang isa nilang kasamahan na nurse rin na positibo rin pala. Naiiyak na lang siya, labis siyang nabahala ngunit sa awa naman ng Diyos ay negatibo ang naging resulta niya ngunit hindi pa rin daw talaga maaalis sa isip ng mga tao na iwasan at magkaroon ng diskriminasyon sa kanila lalo na kapag nakikita silang nakauniporme.

Maraming suliranin ang kanilang dinaranas bilang mga healthworkers na siyang tunay na lumalaban ngayon sa virus, hindi sila nabibigyan ng sapat na pansuporta, wala pa ring pagtaas ng sweldo, magtatiyaga sa noon pa man ay kakarampot na sahod na binibigay sa kanila. Inaprubahan ng pangulo ng Pilipinas ang hazard pay para sa kanila ngunit ito'y nagkakahalaga lamang ng P500.00 kada araw batay sa ipinalabas nila na administrative order no.26 section 1 at nang magsimula na ang GCQ ay inalis na raw itong hazard pay, samantalang lalo naman daw tumataas ang bilang ng mga dapat pa nilang alagaan, ibig sabihin mas lalong kailangan sila.

“Calling ito sa amin, kahit may choice naman kami na 'wag na lamang magtrabaho para sa aming pansariling kaligtasan ngunit hndi mo matatalikuran ang pasyente, hndi na sila iba sa amin parang pamilya na namin sila. Ito ung tawag ng tungkulin. Nurse pa rin kami at kami ang lalaban ngayon hndi pulis, hindi sundalo. Kung wala kami, sino ang maaaring pumalit? Sana nga lang bigyan na kami ng importansiya. Mapataas ang aming sweldo at magkaroon ng mga benepisyong magbibigay kasiguraduhan sa aming kalusugan at buhay..." tuwirang pahayag ni Bb. Lisa. 


\section{Ginang Mae}

Si Ginang Mae (panayam sa messenger, Hunyo 5, 2020), isang simpleng maybahay na may dalawang maliliit na anak. Nawalan ng trabaho ang kaniyang asawa simula pa noong Marso dahil sa ECQ. Sa Bulacan namamasukan ang kaniyang asawa kaya hindi rin minimum wage ang sinasahod nito, pinagkakasya nila ang maliit na kita para sa pang-araw-araw na pamumuhay ngunit mas lalong humirap at naging komplikado ang buhay para sa kanila. Nakikitira lamang sila sa magulang ng kaniyang asawa na pareho nang matatanda at may kapansanan pa. Hindi sila napasama sa mga benepisyaryo ng Social Amelioration Program (SAP) sapagkat miyembro ng 4Ps ang kaniyang biyenan, ngunit dapat daw ay ibilang sila bilang ibang pamilya. Nagbalik-balik daw siya sa barangay upang ilapit ang kaniyang hinaing ngunit bigo lamang siya. Nakapanlulumo lamang daw na kung sino pa ang mga "may kaya", may mga negosyo sa kanilang lugar ay sila pa ang nakatanggap ng P8,000. Sa talaan ng mga benepisyaryo, makikita raw na magkakamag-anak ang naroon, mag-ina o magkapatid na iisang bahay din naman, gayundin ang mga malalapit sa mga opisyal ng barangay. Tila hindi raw ito patas, marami silang mga nagreklamo ngunit hindi rin dininig at sa huli ay walang napala. Ang pabrikang pinapasukan naman ng kaniyang asawa ay nagpaabot nga ng tulong ngunit pautang ito sa kanilang mga manggagawa na may interes, kung gipit ka talaga kakapit sa ganitong sistema. Hindi naman daw sila tumulong bagkus tila ginawa pa nilang negosyo ang kawawang kalagayan ng kanilang mga trabahador.

Naranasan na niya ang manlimos sa mga social media accounts para lang may maipanggatas ang kaniyang mga anak. Kung sino-sino na rin ang kaniyang nilapitan upang mautangan mairaos lang ang delubyong ito. Lahat daw ng pinamimigay sa lugar nila ay talagang tatakbuhin niya para makakuha. Ngayong nag-GCQ niya akala niya ay makababalik na ang asawa niya sa trabaho ngunit hindi rin pala sapagkat pili lamang ang maaaring pumasok. Walang kasiguraduhan daw talaga kung hanggang kailan nila ito kayang malampasan.

\section{Ginoong Nicco}

Isang OFW naman ang ating nakapanayam na nagtatrabaho sa Greater London, United Kingdom sa isang coffee shop bilang barista at dispatcher na itago na lamang natin sa pangalang Ginoong Nicco (panayam sa messenger, Hunyo 6, 2020), 47 taong gulang. Taong 2019 siya nagtungo roon upang maghanap ng bagong oportunidad na hindi maibigay ng Pilipinas. Sa pagsisimula ng lockdown sa kanila, ang mga Briton ay tila hindi nababahala kahit na napakataas na ng kumpirmadong kaso ng COVID-19 sa kanila gayundin ang iba pang mga Europeong bansa. Sa katunayan, nito lamang daw buwan ng Hunyo talagang ipinag-utos ng kanilang gobyerno ang pagsusuot ng face mask. Ayon sa balita ng BBC News, (2020), nagbigay ng datos ang Department of Health and Social Care UK na nasa 283,111 na ang positibong kaso ng may corona virus at 40,261 ang patay noong ika-5 ng Hunyo. Nasa pangatlong may pinakamatataas na bilang ng postibong kaso ng corona virus ang bansang United Kingdom sa buong mundo sa pinakabagong tala noong Hunyo 2 (Statista, 2020).

Ibinahagi din naman ni Ginoong Nicco ang magandang sistema at suporta ng gobyerno sa kanilang mamamayan. Hindi naghihirap ang mga tao kahit may pandemiko dahil sagot daw ng pamahalaan ang $80 \% \mathrm{ng}$ kanilang sahod at $20 \%$ naman ay ibibigay naman ng kumpanya. Hindi nababahala ang mga tao na wala silang kakain dahil kahit nasa mga bahay lamang ay patuloy pa rin ang kita nila. Kahit umabot pa iyan ng 3-5 buwan ay suportado sila ng UK government. Libre ang healthcare at mass testing ngunit prayoridad nila ang mga National Health Services (NHS ang tawag sa kanila).

Samantala ang kaniyang pinapasukang trabaho ay bumaba din ang kita na nasa 10- 20\% na lamang kung ikukumpara sa regular na kita nila noong wala pang pandemya. Puro take-out na lamang ang kanilang store sa pamamagitan ng online delivery at silang mga pinapasok pa ay nag-iinventory na lamang. Hindi maaalis sa kaniya ang pangamba at takot na baka makapagdala siya ng virus dahil araw-araw siyang lumalabas, kaya pag-uwi agad sa bahay ay maliligo kaagad siya dahil naroon pa rin ang alalahanin kung mabubuhay pa siya at makauuwi sa pamilya sa Pilipinas. 


\section{Kongklusyon at rekomendasyon}

Batay sa mga inilahad na mga naratibo, nakabuo ng mga sumusunod na kongklusyon:

1. Napakalaking gampanin ngayon ng internet world sa pamumuhay ng mga Pilipino. Sa panahong lahat ay nasa bahay na lamang, halos lahat ay nakatutok sa kanilang mga social media accounts. Ang mga ito lalo na ang Facebook ay naging pangunahing pinagkukunan ng napapanahong impormasyon. Nagiging daan din upang mailabas ng tao ang kaniyang pagiging malikhain sa mga nakatatawang videos nang sa gayon ay maibsan man lamang ang takot na dulot ng pandemya.

2. Ang magastos at masakripisyong paraan ng pag-ani ng sertipiko ng mga guro para sa kanilang promotional rankings at self- development ay naging libre nalang sa social media at napakarami pa, minsan hindi ka na makapili sa kung ano ang panonoorin mo dahil nagsasabay-sabay ang lahat. Aksesibol pa ito sa mga guro saanmang dako ng Pilipinas kahit walang pera.

3. Sa isang iglap ay biglang nag-iba ang meeting room para sa mga pagpupulong hindi na isang silid, hindi na rin function hall para sa mga seminars o silid-aralan para sa pagtuturo. Ito na ngayon ang ating bagong paraan upang makapamuhay, Lumitaw ang maraming pagbabago. Nagtagpo ang tradisyon at teknolohiya kaya isinilang ang bagong kahimtang ng lipunang Pilipino.

4. Hindi lamang distansiya ng tao sa tao ang naganap, kundi maging ang distansya ng tao sa kaniyang pangangailangan upang mabuhay. Hihilumin ang bayan mula sa pandemyang ito at nawa'y kasabay nito ay gagamutin din ang iba pang sakit ng lipunan na noon pa man ay hindi na malunasan.

5. Nais gamitin ng mananaliksik bilang pangwakas na kongklusyon ang isang illustration post ni Srishtinot (2020) na orihinal na isinulat ni Eiver Ky Villegas na naipakita sa simpleng paglalarawan at istorya ang iba't ibang kalagayan ng mga Pilipino ngayong pandemiko sa kuwento ng bangka. Ang katotohanan, nasa iisang dagat lang tayo ngunit hindi lahat ay pare-pareho ng bangkang sinasakyan. May iba na nasa magara at komportableng yate, ang iba ay nasa matibay na barko, mayroong nasa bangkang gawa lamang sa kahoy na kailangang isagwan nang manwal para umusad, nasa mga balsa naman ang iba na pinipilit na makakapit makasalba lang sa araw-araw at marami ang tuluyan nang nalunod.

Batay sa mga nabuong kongklusyon ay iminumungkahi ang mga sumusunod:

1. Bagaman mabilis ang akses ng mga napapanahong balita sa social media o internet world ay dapat maging mapanuri pa rin ang lahat sa pinagkukunan ng mga datos na paniniwalaan at ibabahagi rin sa iba sapagkat nagsusulputan ang mga artikulo o balita mula sa mga kahina-hinalang mga websites na ang layon lamang ay manira ng kapwa o isang organisasyon. Ang bawat isa ay dapat na maging responsable sa paggamit ng social media lalo na ngayong pandemiko.

2. Mas matiyak sana na ang mga paksang ibinabahagi sa mga webinars ay hindi palasak o pauulit-ulit na lamang at ang magiging tagapagsalita ay tunay na maalam ukol doon.

3. Magkaroon pa ng mga naratibong maisusulat at maitatabi sapagkat ang nangyaring pandemikong ito ay bahagi na nang kasaysayan ng buong mundo at mas mainam na may babalikan tayong mga tala ng mga mahahalagang danas at pangyayari sa panahong ito.

\section{Mga Sanggunian}

ABS-CBN News. (2020, May 12). Modified, enhanced, general quarantine: What's the difference?

https://news.abscbn.com/business/05/12/20/modifiedenhanced-general-quarantine-whats-the-difference

Ambisyon Natin 2040. (2016). NEDA releases survey results of ambisyon natin 2040. 
Pagdanhay at pagtunghay ng mga naratibong danas dulot ng COVID-19 sa Lipunang Pilipino

http://2040.neda.gov.ph/2016/07/21/neda-releases-survey-results-of-ambisyon-natin-2040/

BBC News. (2020, June 5). Coronavirus UK map: How many confirmed cases are there in your area? https://www.bbc.com/news/uk-51768274

CNN Philippines. (2020). Over 2 million workers lose jobs as COVID-19 quarantine measures continue- DOLE. https://www.cnnphilippines.com/news/2020/4/26/2-million-workers-displacedquarantine-COVID-19-pa ndemic.html

Enriquez, V. G. (2015). The basis of Filipino psychology in culture and history [Ang batayan ng sikolohiyang Pilipino sa kultura at kasaysayan]. Daluyan Journal, 1, 35-36. https://journals.upd.edu.ph/index.php/djwf/article/view/4948/4457

Esguerra, J. D. (2020, May 12). Breaking: NCR, Laguna, Cebu City placed under modified ECQ until May 31. Inquirer.net.

https://newsinfo.inquirer.net/1273529/breaking-govt-puts-ncrlaguna-cebu-city-under-modified-ecq-until $\underline{-m a y-31}$

Evans, D. (2020). How zoom became so popular during social distancing. https://www.cnbc.com/2020/04/03/how-zoom-rose-to-the-top-during-the-coronaviruspandemic.html

Hazel. (2020, May 19). Fish vendors, arrested and imprisoned in navotas for not having a quarantine pass [Fish vendor, inaresto at nakulong sa navotas dahil walang quarantine pass]. Pinas Balita. https://pinasbalita.org/fish-vendor-inaresto-atnakulong-sa-navotas-dahil-walang-quarantine-pass/

IBON Media \& Communications. (2020). The family living wage, as of february 2020. https://www.ibon.org/the-family-living-wage-as-of-february-2020/

Leskin, P. (2020, January 24). Inside the rise of tiktok, the viral video-sharing app whose ties to China are raising concerns in the US. Business Insider.

https://www.businessinsider.com/tiktok-app-online-website-video-sharing-2019-7

Llego, M. A. (2019). 2019 code of ethics for professional teachers explained [Blogpost]. https://depedtambayan.net/the-code-of-ethics-for-professional-teachers/\#ARTICLE_XI_\%E2\%80\%93 THE_TEACHER_AS_A_PERSON

Pagdanhay. (n. d.). Diksyunaryo.Ph. https://diksiyonaryo.ph/

Philippine Star. (2020, May 11). Construction workers. https://web.facebook.com/PhilippineSTAR/posts/construction-workers-who-were-not-able-to-return-ho me-before-the-implementation-/1771362216350785/?_rdc=1\&_rdr

San Juan, M. (2020). Ang manggagawang Pilipino [Webinar]. Tanggol Wika. https://www.facebook.com/TANGGOLWIKA/videos/2642333722701543/

Srishtinot. (2020, May 28). Boat story \#pandemic2020 \#pandemicart \#covid_19 \#cartoonist [Facebook post]. https://www.facebook.com/5739751163650 30/posts/933068230455715/

Statista. (2020). Number and change of coronavirus (COVID-19) cases and deaths among the most impacted countries worldwide as of June 2, 2020. https://www. statista.com/statistics/1105264/coronavirus-covid-19-cases-most-affected-countries-worldwide/

Tan, M. L. (2020). Class lectures: Research methods interviewing [Lektura sa klase: Research methods interviewing] [hand-outs]. University of the Philippines-Diliman.

Tiangco, M. K. (2020, April 9). TikTok donates US\$1 M to PGH. Manila Bulletin. https://news.mb.com.ph/2020/04/09/tiktok-donates-us1-m-to-pgh/

Tung, J. (2020). Zoom: Prepared for a pandemic. https://digital.hbs. edu/platform-digit/Submission/zoom-prepared-for-a-pandemic/

US Chamber of Commerce. (2020). 15 small businesses thriving during coronavirus. https://www.uschamber.com/co/start/strategy/coronavirus-successful-businesses

Villan, V. (2020a, May 21). His only translation of "new normal" or "new norm" is "new condition" from the Hiligaynon language [Ang salin lang naman niyang "new normal" o "new norm" ay "bagong kahimtang" mula sa wikang Hiligaynon] [Facebook status update]. https://m.facebook.com/story.php?story fbid=661841131331527\&id=100025169378809

Villan, V. (2020b, May 21). Whenever we are not enemies of our fellow man but the evil conscience that exists 
Lagunsad, R. I. L.

here [Kelan man di natin kaaway ang ating kapwa tao kundi ang masamang budhi na umiiral ditto] [Facebook comment reply]. Nakuha mula

https://m.facebook.com/story.php?story_fbid=664813504367623\&id=100025169378809

World Health Organization. (2020). WHO timeline - covid-19.

https://www.who.int/news-room/detail/27-04-2020-who-timeline---covid-19

44 Consortia Academia Publishing (A partner of Network of Professional Researchers and Educators) 